\title{
Gender Differences in Perceptions of Family Planning and Fertility Preferences in Northern Nigeria
}

\author{
Ryoko Sato* \\ Harvard T H Chan School of Public Health, USA
}

Submission: January 05, 2021; Published: January 11, 2021

*Corresponding author: Ryoko Sato, Harvard T H Chan School of Public Health, USA

\section{Abstract}

Objective: We evaluate differences between women and men regarding information level, perceptions, preferences around fertility, and family planning use using a primary data collection method.

Methods: The study was conducted in Jada local government area of Adamawa state, the northeastern Nigeria among married women between 15 and 45 years or married men whose wives were between 15 and 45 years. We analyze the data to compare the differences in fertility preference and knowledge and preference regarding family planning between women and men.

Results: We find that married women prefer significantly fewer children than men. However, both men and women show high satisfaction with their spouses in terms of fertility choices. The level of understanding about family planning methods, as well as the intention to use family planning, was the same between women and men. Men qualitatively viewed women's use of family planning more favorably than women themselves did.

Conclusion: Contrary to the findings from existing research, men's opposition to women's use of family planning is unlikely to be a major barrier to the demand for family planning among women in northern Nigeria. Gender Differences in Perceptions of Family Planning and Fertility Preferences in Northern Nigeria

Keywords: Gender differences; Family planning preferences; Fertility preferences; Nigeria

\section{Introduction}

Nigeria has one of the highest fertility rates in the world at 5.53 . This high fertility rate threatens the sustainable economic growth of the country, poverty alleviation efforts, and the improvement of maternal and child health outcomes [1]. The unmet need for family planning, together with the high fertility rate, contributes to high rates of unintended pregnancies and unsafe abortions annually [2].

Promoting the use of family planning is an effective way to control the fertility rate and reduce the number of unwanted pregnancies [3]. Despite this benefit, the use of family planning methods is limited in Nigeria, making slow progress over the last 15 years. The lack of information about the importance of birth spacing and the benefits of family planning has been cited as one of the important reasons for low uptake [4]. According to the
Demographic Health Survey conducted in Nigeria in 2013, women in the northern part of the country were less likely to have heard of a family planning method. On the other hand, there were fewer differences in contraception knowledge among men across these categories [5].

In addition to examining knowledge of family planning methods, understanding fertility preference is important to assess women's desire for children and the extent of unwanted pregnancies. In patriarchal African communities, men and husbands are important decision makers in regards to family planning use and fertility decisions [6]. Therefore, explorations of barriers to contraception use, interventions to increase their use, and determinants of fertility choices should also include an understanding of the role of men. 
A few studies have examined discordance in fertility preferences and family planning between men and their wives in Nigeria [7]. However, no recent study has examined these preferences in a community-based survey in northern Nigeria with an emphasis on capturing factors that determine differential demand for children between men and women and their perceptions on family planning. Given the limited literature available, it is important to fill the gap to deepen our knowledge on the differences in preference by gender, as it can be one of the main barriers to the uptake of family planning methods, as suggested by extant studies [8].

\section{Methods}

\section{Study setting and participant selection}

The study was conducted in Jada local government area of Adamawa state, where contraception use is extremely limited. Individuals were eligible to participate in this study if they were married women between 15 and 45 years or married men whose wives were between 15 and 45 years and resided in one of the four settlements within the catchment areas of two health clinics: Jada Primary Health Clinic I and Kojoli Primary Health Clinic. These settlements were selected to provide a range of contexts around family planning. Households within each settlement were visited to identify and interview eligible respondents until each interviewer reached the target number of respondents: three women and three men per day. The total number of participants in this study was 95 women and 96 men.

\section{Data collection}

Data were collected in October 2018. The interview instrument was designed to elicit the following pieces of information via a survey format: sociodemographic characteristics, fertility preference, and knowledge and preference regarding family planning, as well as its use. Interviews were held in a private area, and respondents' spouses were not around during the interview. Men were asked about their wives. If a man had more than one wife, specific questions were asked about his youngest wife. This was to simplify the procedure of the data collection for interviewers. Data were gathered by six locally based trained health workers. The lead author of the study supervised the data collection to ensure quality control.

\section{Data Analysis}

Data were checked for completeness and inconsistencies after the data collection. CSPro version 6.1 was used for data entry, and data were exported to Stata version 15. Descriptive statistics were computed for characteristics collected during the baseline survey, and OLS regression analysis was used to compare the differences in fertility preference and knowledge and preference regarding family planning between women and men.

\section{Ethical considerations}

Ethical clearance was obtained from the Health Research Ethical Committee of Adamawa State Ministry of Health. Verbal informed consent was obtained from all study participants, and they were assured of voluntary withdrawal from the study at any point. Each study participant was given 300 naira as compensation for his or her time.

\section{Result}

A total of 197 eligible people were approached. Among them, 95 married women and 96 married men were interviewed, yielding a response rate of $96.9 \%$. One woman was later revealed to be ineligible due to her age, and five households refused to participate in the study.

\section{Differences between women and men}

Table 1 shows differences in sociodemographic characteristics between men and women. The average age among women was 29.41 years old, and the women were 11 years younger than the men. Women were much less educated than men; the proportion of women who had completed secondary education or more was 37.1 percentage points less than the proportion of men who had done the same. We also asked for the ages and education levels of interviewees' spouses. Women were 13 to 14 years younger than their husbands, and women were much less educated than their husbands; $34.7 \%$ of women had received at least secondary education, while $68.4 \%$ of women's spouses had secondary education. The majority of respondents, over $85 \%$, were Muslim, regardless of gender. Women were 12.7 percentage points less likely to have paid work than men.

Table 1: Summary Statistics on Sociodemographic Characteristics.

\begin{tabular}{|c|c|c|c|c|c|c|}
\hline \multirow[t]{2}{*}{ Variable } & & \multicolumn{2}{|c|}{ Women $(\mathrm{N}=95)$} & \multicolumn{2}{|c|}{ Men $(\mathrm{N}=96)$} & \multirow{2}{*}{ Difference } \\
\hline & \multicolumn{2}{|c|}{ Mean Std. Dev. } & \multicolumn{2}{|c|}{ Mean Std. Dev. } & & \\
\hline Age & No education & 29.411 & 7.167 & 40.432 & 8.811 & $-11.021^{* * *}$ \\
\hline Spouse's age & Primary school & 42.71 & 9.711 & 26.896 & 6.811 & $15.814^{* * *}$ \\
\hline \multirow[t]{4}{*}{ Education } & Secondary school or more & & & & & \\
\hline & & 0.4 & 0.492 & 0.1250 .146 & 0.332 & $0.275^{* * *}$ \\
\hline & No education & 0.253 & 0.437 & 0.719 & 0.355 & $0.107^{*}$ \\
\hline & Primary school & 0.347 & 0.479 & 0.3130 .240 & 0.452 & $-0.371^{* * *}$ \\
\hline Spouse's Education & Secondary school or more & & & & & \\
\hline
\end{tabular}


Journal of Gynecology and Women's Health

\begin{tabular}{|c|c|c|c|c|c|c|}
\hline & & 0.158 & 0.367 & 0.4480 .896 & 0.466 & $-0.155^{* *}$ \\
\hline & & 0.158 & 0.367 & & 0.429 & -0.082 \\
\hline & Chamba & 0.684 & 0.467 & 0.3230 .448 & 0.5 & $0.236^{* * *}$ \\
\hline \multirow[t]{3}{*}{ Religion = Muslim } & Fulani & 0.853 & 0.356 & 0.3750 .521 & 0.307 & -0.043 \\
\hline & Chamba & 0.432 & 0.498 & 9.298 & 0.47 & 0.109 \\
\hline & Fulani & & & & & \\
\hline \multirow[t]{3}{*}{ Spouse Ethnicity } & & 0.411 & 0.495 & 1.344 & 0.5 & -0.037 \\
\hline & & & & 3332.5 & & \\
\hline & & 0.326 & 0.471 & 0.9793 .240 & 0.487 & -0.049 \\
\hline Years of Marriage & & 0.484 & 0.502 & 0.281 & 0.502 & -0.037 \\
\hline Number of Wife & & 11.147 & 6.825 & & 7.134 & 0.14 \\
\hline $\begin{array}{l}\text { Earning per capita last } \\
\text { month }\end{array}$ & & 1.484 & 0.742 & & 0.63 & -23.334 \\
\hline Has paid work & & 3309.2 & 5773 & & 4081.9 & $-0.127^{* * *}$ \\
\hline \multirow{2}{*}{$\begin{array}{l}\text { Number of children } \\
\text { alive }\end{array}$} & & 0.853 & 0.356 & & 0.144 & 0.55 \\
\hline & & 3.789 & 2.572 & & 3.08 & $0.119^{*}$ \\
\hline Child died & & 0.4 & 0.492 & & 0.452 & \\
\hline
\end{tabular}

Notes: * significant at $10 \%$; ${ }^{* *}$ significant at $5 \%$; ${ }^{* * *}$ significant at $1 \%$

Table 2 presents the differences in fertility preferences by gender. The average number of children women wanted in the future is significantly less than the number of children men wanted. While women on average would like to have 3.6 more

children in the future and 0.67 children in the next 2 years, they wanted 3.07 fewer children in the future than men did, and they wanted 1.6 fewer children in the next 2 years than men.

Table 2: Summary Statistics on Fertility.

\begin{tabular}{|c|c|c|c|c|c|}
\hline \multirow{2}{*}{$\begin{array}{c}\text { Variable } \\
\text { Own preference }\end{array}$} & \multirow{2}{*}{\multicolumn{2}{|c|}{$\begin{array}{l}\text { Women (N=95) } \\
\text { Mean Std. Dev. }\end{array}$}} & \multirow{2}{*}{\multicolumn{2}{|c|}{$\begin{array}{c}\text { Men }(\mathrm{N}=96) \\
\text { Mean Std. Dev. }\end{array}$}} & \multirow{2}{*}{ Difference } \\
\hline & & & & & \\
\hline Number of children wanted in future & 3.581 & 3.424 & 6.649 & 7.316 & $-3.068^{* * *}$ \\
\hline Number of children wanted in 2 years & 0.674 & 0.554 & 0.833 & 0.592 & $-0.160^{*}$ \\
\hline Perceptions on Spouses' preference & & & & & \\
\hline Spouse wants the same \# children as I do & 0.453 & 0.5 & 0.427 & 0.497 & 0.026 \\
\hline Spouse wants more \# children than I do & 0.347 & 0.479 & 0.313 & 0.466 & 0.035 \\
\hline Spouse wants less \# children than I do & 0.105 & 0.309 & 0.167 & 0.375 & -0.061 \\
\hline Don't know how many children spouse wants & 0.084 & 0.279 & 0.094 & 0.293 & -0.01 \\
\hline Very happy with spouse on children & 0.821 & 0.385 & 0.792 & 0.408 & 0.029 \\
\hline Beliefs & & & & & \\
\hline (self) having many children is good & 0.158 & 0.367 & 0.188 & 0.392 & -0.03 \\
\hline (spouse) having many children is good & 0.147 & 0.356 & 0.135 & 0.344 & 0.012 \\
\hline (community) having many children is good & 0.189 & 0.394 & 0.115 & 0.32 & 0.075 \\
\hline Spacing is good & 0.516 & 0.502 & 0.615 & 0.489 & -0.099 \\
\hline
\end{tabular}

Notes: * significant at $10 \%$; ${ }^{* *}$ significant at $5 \%$; ${ }^{* *}$ significant at $1 \%$

Perceptions about their spouse's fertility preferences, on the other hand, were not significantly different between women and men. Statistically, the same proportion of women and men thought that their spouse wanted the same number of children as they did, and the same proportion of women and men thought that their spouse wanted more children than they did. The proportion of women who were very happy with their husbands in terms of the number of children they had is the same as the proportion of men felt the same way regarding their wives. 
Among women, $15.5 \%$ of them thought that having many children was good, and around the same proportion of women $(14.7 \%)$ thought that their husband thought the same, and $18.9 \%$ of women thought that people in their community thought that having many children was good. These percentages were statistically the same as the percentages among men. The perception about birth spacing is similar among women and men from their own perspective, their spouse's perspective, and the community's perspective.

Table 3 presents family planning use. The use of family planning self-reported by women and reported by men about their wives was statistically the same. Only $7.4 \%$ of women were currently using family planning, while $17.2 \%$ of them had ever used modern family planning. Among ever-users out of the female interviewees, $56.3 \%$ had used injectables, $37.5 \%$ had used oral pills, and the remaining $6.3 \%$ had used implants. Among male respondents' wives, $5.2 \%$ were currently using family planning, and $13.5 \%$ had ever used family planning. Among ever-users out of male interviewee's wives, 53.8\% had used oral pills, followed by injectables (46.2\%).

Table 3: Summary Statistics on Family Planning Use.

\begin{tabular}{|c|c|c|c|c|c|}
\hline \multirow{2}{*}{ Variable } & \multicolumn{2}{|c|}{ Women (N=95) } & \multicolumn{2}{c|}{ Men (N=96) } & \multirow{2}{*}{ Difference } \\
\cline { 2 - 5 } & Mean & Std. Dev. & Mean & 0.052 & 0.2230 .135 \\
\hline FP now & 0.0740 .172 & 0.263 & $\mathrm{~N}=13$ & 0.344 & 0.022 \\
\hline FP ever & $\mathrm{N}=16$ & 0.379 & & & \\
\hline Among Ever FP user & 0.063 & & 0 & 0.0000 .462 & 0.063 \\
\hline Ever used implant & 0.563 & 0.25 & & 0.519 & 0.101 \\
\hline Ever used injetables & 0.375 & 0.512 & 0.538 & 0.519 & -0.163 \\
\hline Ever used oral pills & & 0.5 & & & \\
\hline
\end{tabular}

Notes: Among men, we asked about the family planninguse among men's wives. * significant at $10 \%$; ${ }^{* *}$ significant at $5 \%$; ${ }^{* * *}$ significant at $1 \%$

Table 4 presents the knowledge, perceptions, and intention of family planning use. The knowledge level of each method of family planning was statistically the same between women and men. Among eight different methods of family planning (family planning, female sterilization, male sterilization, IUD, injectables, implants, oral pills, and condoms), women knew about slightly over half $(4.55$, or $56.8 \%)$ of them. While the lowest proportion of women knew about male sterilization (16.8\%), 76.8\% of women knew about injectables. Women had correct knowledge about $56.5 \%$ of family planning methods. There was no statistical difference in knowledge of family planning between women and men.

Table 4: Summary Statistics on Family Planning.

\begin{tabular}{|c|c|c|c|c|c|}
\hline \multirow{2}{*}{ Variable } & \multicolumn{2}{|c|}{ Women $(\mathrm{N}=95)$} & \multicolumn{2}{|c|}{ Men $(\mathrm{N}=96)$} & \multirow{2}{*}{ Difference } \\
\hline & Mean & Std. Dev. & Mean & Std. Dev. & \\
\hline \multicolumn{6}{|l|}{ Knowledge on FP } \\
\hline \# FP methods known (out of 8) & & 2.444 & 4.698 & 2.367 & \\
\hline$\%$ FP methods known & 4.547 & 0.306 & 0.587 & 0.296 & \\
\hline Know Female sterilization & 0.568 & 0.482 & 0.365 & 0.484 & -0.151 \\
\hline Know Male sterilization & 0.358 & 0.376 & 0.25 & 0.435 & -0.019 \\
\hline Know IUD & 0.168 & 0.453 & 0.292 & 0.457 & -0.007 \\
\hline Know Injectables & 0.284 & 0.424 & 0.792 & 0.408 & -0.082 \\
\hline Know Implants & 0.768 & 0.467 & 0.583 & 0.496 & -0.007 \\
\hline Know Oral Pills & 0.684 & 0.437 & 0.781 & 0.416 & -0.023 \\
\hline Know condoms & 0.747 & 0.467 & 0.781 & 0.416 & 0.101 \\
\hline \# correct knowledge on FP (out of 7) & 0.684 & 2.333 & 3.74 & 2.314 & -0.034 \\
\hline \% correct knowledge on FP (out of 7) & 3.958 & 0.333 & 0.534 & 0.331 & -0.097 \\
\hline Perceptions & & & & & 0.218 \\
\hline Injetables make women never get pregnant again & 0.565 & & & & 0.031 \\
\hline IUD make women never get pregnant again & & 0.294 & 0.115 & 0.32 & \\
\hline Implants make women never get pregnant again & 0.095 & 0.224 & 0.083 & 0.278 & -0.02 \\
\hline
\end{tabular}


Journal of Gynecology and Women's Health

\begin{tabular}{|c|c|c|c|c|c|}
\hline Implants are inserted to vagina & 0.053 & 0.202 & 0.063 & 0.243 & -0.031 \\
\hline Oral pills cause cancer & 0.042 & 0.032 & 0.021 & 0.144 & -0.02 \\
\hline FP is evil & 0.032 & 0.294 & 0.208 & 0.408 & 0.011 \\
\hline FP is good for women & 0.095 & 0.385 & 0.125 & 0.332 & $-0.114^{* *}$ \\
\hline FP is good for babies & 0.179 & 0.334 & 0.146 & 0.355 & 0.054 \\
\hline $\mathrm{FP}$ is dangerous for women & 0.126 & 0.322 & 0.177 & 0.384 & -0.02 \\
\hline FP is dangerous for husbands & 0.116 & 0.463 & 0.344 & 0.477 & -0.061 \\
\hline Community & 0.305 & 0.394 & 0.26 & 0.441 & -0.038 \\
\hline Women think FP is good & 0.189 & & & & -0.071 \\
\hline Men think FP is good & 0.105 & & & & \\
\hline FP is a taboo in the community & & 0.309 & 0.125 & 0.332 & -0.02 \\
\hline Men don't like FP & & 0.224 & 0.115 & 0.32 & -0.062 \\
\hline Intention & 0.053 & 0.437 & 0.219 & 0.416 & 0.034 \\
\hline Intention of FP now or in the future & 0.253 & 0.5 & 0.49 & 0.503 & 0.058 \\
\hline Among Intention $=$ Yes & 0.547 & 0.437 & 0.82 & 0.384 & -0.076 \\
\hline \multicolumn{6}{|l|}{ Method of future FP (female sterlization) } \\
\hline Method of future FP (IUD) & $0.747 \mathrm{~N}=71$ & & $\mathrm{~N}=79$ & & \\
\hline Method of future FP (implant) & 0 & 0 & 0 & 0 & 0 \\
\hline Method of future FP (injectables) & 0 & 0 & 0 & 0 & 0 \\
\hline \multirow[t]{3}{*}{ Method of future FP (oral pills) } & 0.366 & 0.485 & 0.367 & 0.485 & -0.001 \\
\hline & 0.324 & 0.471 & 0.304 & 0.463 & 0.02 \\
\hline & 0.197 & 0.401 & 0.19 & 0.395 & 0.007 \\
\hline
\end{tabular}

Notes: * significant at $10 \% ;{ }^{* *}$ significant at $5 \% ;{ }^{* * *}$ significant at $1 \%$

There was no difference in most of the perceptions about family planning, both negative and positive. Among women, 9.5\%, $5.3 \%$, and $4.2 \%$ of them respectively thought that infertility would be caused by injectables, IUDs, and implants. A small proportion of women $(3.2 \%)$ thought that implants were inserted into the vagina, which is false information. Over 15\% (17.9\%) of women thought that family planning was evil, while $12.6 \%$ and $11.6 \%$ of women respectively thought that family planning was good for women and for babies who are to be born. About one-third $(30.5 \%)$ and one-fifth (18.9\%) of women respectively thought that family planning was dangerous for women and for husbands. These perceptions were statistically the same among women and men.

The exception is on the cancer risk caused by oral pills. While 9.5\% of women thought that oral pills caused cancer, $20.8 \%$ of men thought so. The difference is statistically significant (11.4 percentage points). Finally, the intention of family planning use in the future is also statistically identical between women and men. For men, we asked their intention to recommend family planning use to their spouses. On average, $74.7 \%$ of women and $82.3 \%$ of men had the intention to recommend it to their spouses.

\section{Discussion}

This study compared differences in preference for and understanding of fertility and family planning between married women and men. Although women and men were not always paired in our sample, we consider that the characteristics of the interviewed men reflect the similar characteristics of interviewed women's husbands due to the same selection criteria we used for interviewed women and men's spouses.

We found a large gap in sociodemographic characteristics between women and men, which might lead to unbalanced decision power regarding family planning use. Women were much younger and much less educated than their husbands. Women were also much less likely to have paid work than men. In this setting, demand for family planning among women can be hindered by the unbalanced power in decision-making when men have different perceptions from women [9-12]. Our study also revealed that men want significantly more children than women do. This difference in fertility preference is another risk factor for the low uptake of family planning among women.

Contrary to this concern, however, we found that most women $(82.1 \%)$ were very happy with their spouses in terms of fertility preferences. Women did not perceive differently from men in terms of the number of children they thought their spouses wanted to have. We also did not observe any significant differences in terms of perceptions on birth spacing between women and men. Thus, although there is a gap in fertility preferences between women and men, wives and husbands seem to have good understandings of each other and similar understandings of the important reproduction practices. 
Our study also implies that men have deeper knowledge and a potentially more favorable view on family planning than women. First, the knowledge level of family planning methods was higher, although insignificantly so, among men than among women. Second, we observed that men were also more likely, although insignificantly so, to acknowledge that family planning is good and less likely to think that it is evil. We also found that the intention to use family planning in the future was qualitatively higher among men (their intention to recommend that their wives use family planning) than among women (their own intention to use family planning), although the difference was insignificant. It is also important to note that that the intention of future use was high for both women and men: $74.7 \%$ and $82.3 \%$, respectively.

Third, although men were also more likely to have concerns about side effects of family planning such as infertility and cancer than women, this might indicate the higher level of knowledge on family planning among men. These results are consistent with some extant studies, which have observed the high level of knowledge and favorable attitude toward family planning among men in Africa [13,14], while other studies found that African men have negative attitudes toward family planning [6].

Overall, our findings consistently indicate that it is unlikely that men's perceptions are barriers to women's use of family planning, and there is no significant disagreement in terms of decisionmaking on family planning use. This finding is not consistent with the findings of Duze and Mohammed [6] from northern Nigeria. However, as Bietsch [14] pointed out, it is possible that men have increased their acceptance of family planning in recent years. We need to be cautious about the interpretation of the results, however, especially the satisfaction with spouses in terms of fertility preferences. It is possible that wives and husbands might not have been discussing family planning use as an option as well as their fertility choices, given the extremely low rate of family planning use. Tumlinson et al. [15] observed that in Kenya, while $23-30 \%$ of men and women never discussed family planning with their partners, about $70 \%$ of those who never discussed family planning perceived that their partners and they were in agreement in terms of fertility desires.

Our study has several limitations. First, the sample was not randomly selected; thus, it might not be representative. Although we made sure that we approached all the households, this method could still cause some bias. Thus, we do not claim the external validity of the study. Second, it is challenging to evaluate the comparison between women's intention to use family planning and men's intention to recommend that their wives use family planning. It might be easier for men to recommend use to their wives than for women to actually use family planning [16-19].

\section{Conclusion}

This paper evaluates the differences in fertility preferences and knowledge and preferences regarding family planning between married women and men in northern Nigeria, where family planning utilization is extremely low. We found that the married women had a preference for significantly fewer children than men. However, this difference in fertility preferences did not seem to cause dissatisfaction with their spouses in terms of fertility from both women's and men's perspectives. We additionally found that the level of understanding about family planning methods was statistically the same between women and men, and that the intention to use family planning was also the same. Furthermore, we found that, qualitatively, men viewed women's use of family planning more favorably than women themselves did. These results indicate that, contrary to the findings from existing papers, men's opposition to women's use of family planning is unlikely to be a major barrier to the demand for family planning among women in northern Nigeria.

\section{Declaration of Interest}

The authors declare that they have no known competing financial interests or personal relationships that could have appeared to influence the work reported in this paper.

\section{Acknowledgement}

a) We are grateful to Abdullahi Belel and the Adamawa State Primary Health Care Development Agency for their cooperation and support throughout the project implementation. We give special thanks to Benjamin Fintan and the field team who devoted themselves to the project.

\section{References}

1. Casterline, John B (2010) Determinants and consequences of high fertility: a synopsis of the evidence - portfolio review (English). World Bank, Washington DC, USA.

2. Monjok E (2010) Contraceptive practices in Nigeria: Literature review and recommendation for future policy decisions. Open Access Journal of Contraception 1: 9 .

3. Singh S (2009) Adding it up: the costs and benefits of investing in family planning and maternal and newborn health. Alan Guttmacher institute : with UNFPA, New York, USA.

4. Haider TL, Sharma M (2013) Barriers to family planning and contraception uptake in sub-saharan africa: a systematic review. Int $Q$ Community Health Educ 33(4): 403-413.

5. National Population Commission and ICF International (2014) Nigeria Demographic and Health Survey 2013. National Population Commission and ICF International, Rockville, Maryland, USA.

6. Daze MC, Mohammed IZ (2006) Male knowledge, attitude, and family planning practices in Northern Nigeria. Afr J Reprod Health 10(3): 5365.

7. Isiugo-Abanihe UC (1994) Reproductive motivation and family-size preferences among Nigerian men. Stud Fam Plann 25(3): 149-161.

8. Greene ME, Mehta M, Pulerwitz J, Wulf D, Bankole A, et al. (2006) Involving men in reproductive health: Contributions to development. Background paper to the report Public choices, private decisions: Sexual and reproductive health and the Millennium Development Goals. Millennium Project, Washington DC, USA. 
9. Mboane R, Bhatta MP (2015) Influence of a husband's healthcare decision making role on a woman's intention to use contraceptives among Mozambican women. Reprod health 12: 36

10. Bankole A, Singh S (1999) Couple's fertility and contraceptive decision - making in developing countries: hearing the man's voice. Int Fam Plan Perspect 24(1): 15-28.

11. Akinrinola B (1995) Desired fertility and fertility behavior among the Yoruba of Nigeria: a study of couple preferences and subsequent fertility. Popul Stud (Camb) 49(2): 317-328.

12. Casterline JB, Sathar ZA, Huque UM (2001) Obstacles in contraceptive use in Pakistan: a study in Punjab. Stud Fam Plann 32(2): 95-110.

13. Mbizvo MT, Adamchak DJ (1991) Family planning knowledge, attitudes, and practices of men in Zimbabwe. Stud Fam Plann 22(1): 31-38.

14. Bietsch KE (2015) Men's attitudes towards contraception in SubSaharan Africa. Afr J Reprod Health 19(3): 41-54.
15. Tumlinson K, Speizer IS, Davis JT, Fotso JC, Kuria P, et al. (2013) Partner communication, discordant fertility goals, and contraceptive use in urban Kenya. Afr J Reprod Health 17(3): 79-90.

16. Cleland JG, Ndugwa RP, Zulu EM (2010) Family planning in sub-Saharan Africa: progress or stagnation? Bull World Health Organ 89(2): 137-143.

17. Hardee K, Croce-Galis M, Gay J (2017) Are men well served by family planning programs? Reproductive health 14(1): 14

18. The World Bank, World Bank Open Data (2016) Total fertility rate, infant mortality rate.

19. United Nations, Department of Economic and Social Affairs, Population Division (2017) World Population Prospects: The 2017 Revision, Key Findings and Advance Tables. Working Paper No. ESA/P/WP/248.

\section{Your next submission with Juniper Publishers} will reach you the below assets

- Quality Editorial service

- Swift Peer Review

- Reprints availability

- E-prints Service

- Manuscript Podcast for convenient understanding

- Global attainment for your research

- Manuscript accessibility in different formats

( Pdf, E-pub, Full Tsext, Audio)

- Unceasing customer service

Track the below URL for one-step submission

https://juniperpublishers.com/online-submission.php 